$\begin{array}{ll} & \text { Etnográfica } \\ \text { etnográfica } & \text { Revista do Centro em Rede de Investigação em }\end{array}$

Antropologia

vol. 15 (3) | 2011

Vol. $15(3)$

\title{
Sofrimento social: idiomas da exclusão e políticas do assistencialismo
}

Social suffering: languages of exclusion and welfare policies

\section{Chiara Pussetti e Micol Brazzabeni}

\section{(2) OpenEdition}

Journals

\section{Edição electrónica}

URL: https://journals.openedition.org/etnografica/1036

DOI: 10.4000/etnografica.1036

ISSN: 2182-2891

\section{Editora}

Centro em Rede de Investigação em Antropologia

\section{Edição impressa}

Data de publição: 1 outubro 2011

Paginação: 467-478

ISSN: 0873-6561

\section{Refêrencia eletrónica}

Chiara Pussetti e Micol Brazzabeni, «Sofrimento social: idiomas da exclusão e políticas do assistencialismo», Etnográfica [Online], vol. 15 (3) | 2011, posto online no dia 23 outubro 2011, consultado o 10 fevereiro 2022. URL: http://journals.openedition.org/etnografica/1036 ; DOI: https:// doi.org/10.4000/etnografica.1036

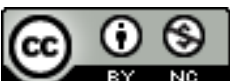

Etnográfica is licensed under a Creative Commons Attribution-NonCommercial 4.0 International License. 


\title{
Sofrimento social: idiomas da exclusão e políticas do assistencialismo
}

\section{Chiara Pussetti e Micol Brazzabeni}

\begin{abstract}
O conceito de sofrimento social emergiu nas últimas décadas como um novo paradigma das ciências sociais e como lente particularmente apropriada para olhar as relações profundas entre a experiência subjetiva do mal-estar e os processos históricos e sociais mais amplos. O presente artigo, e os contributos aqui reunidos, pretendem abordar o sofrimento social sob três pontos de vista que consideramos fundamentais: 1) a forma paradoxal como é retirado ou atribuído o poder às pessoas; 2) a apropriação, por parte das instituições que criam as condições para que o sofrimento tenha lugar, das teorias "salvíficas" sobre a utilidade do sofrimento com vista a um bem-estar maior e futuro da humanidade; 3) a evidência de quanto a assistência, os cuidados, o Estado-social, a proteção humanitária e até os direitos, podem ser manipulados e imbricados na definição e organização das modalidades de pertença ou exclusão nacional, até ao extremo da redução do indivíduo à sua "vida nua".

PALAVRAS-CHAVE: sofrimento social, agência e subjetividade, políticas de assistencialismo.
\end{abstract}

O PRIMEIRO DEBATE SOBRE SOFRIMENTO SOCIAL E INDIVIDUAL QUE estabelecemos com os autores do presente dossiê decorreu no painel "Vivenciar o sofrimento social: suas ambiguidades e articulações”, por nós organizado, no IV Congresso da Associação Portuguesa de Antropologia (APA), que teve lugar em Lisboa em setembro de 2009. Os autores aqui reunidos aceitaram o desafio de sugerir novos elementos de reflexão sobre a temática do sofrimento social que tem merecido grande atenção nas últimas décadas nos campos científicos da antropologia, da sociologia, da psicologia social, como também no âmbito das políticas públicas e económicas internacionais.

Os contributos provêm de pesquisas de terreno de investigadores e docentes que exploram o tema nas suas variadas formas e expressões e que se propõem 
abordar o conceito de sofrimento social em diálogo com questões de género, saúde pública, juventude, exclusão social, migração, pertenças identitárias, desvio social e crime, com especial atenção às suas repercussões nos corpos e nas palavras dos sujeitos afetados.

O objetivo é examinar as causas sociais e as experiências individuais do sofrimento em diferentes contextos, focando em particular questões como: a natureza social e política da doença e do mal-estar; as interfaces entre os significados da pertença identitária e social dos sujeitos, e os saberes e as práticas da agenda institucional dirigida às políticas dos cuidados e do acolhimento; as narrativas subjetivas da dor; a responsabilidade e o posicionamento ético-político dos antropólogos face à produção e implementação de formas de violência e sofrimento social.

É intenção dos autores explicitar também as ambiguidades do sofrimento social através de dois aspetos: por um lado, a análise das intervenções sociais para aliviar o sofrimento dos sujeitos definidos como "vulneráveis" e que frequentemente resultam na sua intensificação; por outro, a problematização das mesmas intervenções, que classificam os sujeitos em categorias rígidas, através de mecanismos complexos de patologização, criminalização e exclusão social. Será dedicada particular atenção às formas locais de agência, individual ou coletiva, para "lidar" com a experiência do sofrimento social, de forma a tentar acompanhar os aspetos processuais da vida social.

O conceito de sofrimento social emergiu nas últimas décadas como lente particularmente apropriada para olhar as relações profundas entre a experiência subjetiva do mal-estar e os processos históricos e sociais mais amplos. O sofrimento, enquanto sentimento humano, foi por muito tempo imaginado como uma experiência inata, ligada ao corpo natural e, portanto, universal - fenómeno pan-humano e pré-cultural, associado aos lugares simbólicos da interioridade -, pouco interessante, nesse sentido, e ainda menos acessível aos métodos da análise sociocultural. Este paradigma universalista está ligado a uma espécie de "realismo ingénuo segundo o qual o amor, a chuva, o casamento, os cultos, as árvores, o sofrimento, a morte, a comida e mil outras formas de realidade têm o mesmo significado para todos os seres humanos" (Bibeau 1995 [1981]: 41). ${ }^{1}$

Todavia, a partir de uma análise mais atenta, o sofrimento revela-se como um facto especificamente social: o primeiro livro (de uma trilogia) de Kleinman, Das e Lock (1997) dedicado à questão do sofrimento social inaugura a linha de pensamento segundo a qual o mal-estar não pode ser observado e explicado independentemente das dinâmicas sociais e dos interesses políticos e económicos que o constroem, reconhecem e nomeiam. As interpretações do sofrimento apelam a uma consciência da história do discurso que as elabora, cujo contexto é sempre o das relações de poder locais. Necessariamente, um olhar crítico 
sobre o sofrimento considera portanto as práticas e estratégias - produzidas e sustentadas dentro de um quadro de relações de poder - que o definem e o aliviam, avaliando a posição dos interlocutores e a ideologia veiculada pelas categorias em jogo.

O sofrimento social, nesta perspetiva, resulta de uma violência cometida pela própria estrutura social e não por um indivíduo ou grupo que dela faz parte: o conceito refere-se aos efeitos nocivos das relações desiguais de poder que caracterizam a organização social. Alude, ao mesmo tempo, a uma série de problemas individuais cuja origem e consequência têm as suas raízes nas fraturas devastantes que as forças sociais podem exercitar sobre a experiência humana. O mal-estar social deriva, portanto, daquilo que o poder político, económico e institucional faz às pessoas e, reciprocamente, de como tais formas de poder podem influenciar as respostas aos problemas sociais. O sofrimento social é o resultado, em outras palavras, da limitação da capacidade de ação dos sujeitos e é através da análise das biografias dos sujeitos que podemos compreender o impacte da violência estrutural no âmbito da experiência quotidiana. ${ }^{2}$

Comparando as biografias dos indivíduos e grupos que protagonizam as histórias reunidas neste dossiê, verificamos que o elemento comum é uma relação incómoda entre sujeito e ordem social: eles partilham a mesma condição de viverem nas margens de organizações sociais, profundamente desiguais, e de não poderem negociar os termos da própria existência. Resulta claro neste ponto o nexo entre violência estrutural, agência e sofrimento social: uma certa configuração da ordem social restringe a capacidade e a liberdade de escolha de certos indivíduos ou grupos.

A capability-based approach, proposta por Amartya Sen (2005, 2009), ${ }^{3}$ sugere que as forças sociais limitam as possibilidades de ação e de escolha dos sujeitos e conformam as suas experiências quotidianas; noutros termos, a maior ou menor liberdade das pessoas depende também da maior ou menor possibilidade de escolherem entre diversas alternativas possíveis. Todas as etnografias do dossiê salientam, no fundo, de forma mais ou menos explícita, a relevância da dialética entre sofrimento, liberdade, subjetividade, agência e responsabilidade - esta última não só das etnografias dos antropólogos e das suas análises, mas também dos sujeitos envolvidos na produção, implementação e disseminação de sofrimento.

2 Paul Farmer (2004) avança com uma proposta teórica fundada sobre o conceito de violência estrutural, definida pelo filósofo Johan Galtung como aquela forma particular de violência que não precisa da ação direta do sujeito para acontecer, mas que é caracterizada pela sua natureza processual e indireta.

3 A "capabilidade" é definida pelo autor como "a oportunidade de ter à disposição", e portanto de poder escolher, "combinações [alternativas] de funcionamentos humanos aos quais atribuímos valor o que uma pessoa é capaz de fazer ou ser” (Sen 2005: 153). Para uma análise mais detalhada da teoria, ver Sen (1985). 
O elemento interessante e pertinente da teoria de Sen sobre o desenvolvimento como liberdade assenta na ligação que o conceito de "capabilidade" estabelece entre liberdade e direitos humanos: "ao avaliarmos as nossas vidas, temos todas as razões para estarmos interessados, não apenas no tipo de vida que conseguimos levar, mas também na liberdade de que realmente dispomos para escolhermos entre estilos e maneiras de viver diferentes" (2009: 227). Desta forma, as teorias sociais que abordam o sofrimento como o resultado de ações, comportamentos ou privações "internas" aos sujeitos esquivam-se a analisar as oportunidades que os indivíduos têm para alcançarem os seus objetivos e os processos através dos quais chegam a escolher ou não. De facto, o que é relevante é a liberdade disponível para efetuar escolhas entre várias opções, e não tanto ou apenas o que realmente temos - o que Sen chama culmination outcomes (2009: 215).

O sofrimento não entra portanto no quotidiano das pessoas só por mero acaso, por contingências específicas da vida ou por existirem mecanismos objetivos de "disfunção social". Como afirma Das (1997), nas sociedades contemporâneas, a violência e o sofrimento infligidos podem ser interpretados como um preço a pagar pelos indivíduos para vivenciarem sentimentos de pertença identitária e social - uma "teodiceia secular" que funciona quer como instrumento social para enfrentar as frustrações, quer como instrumento de poder para explicar e justificar o sofrimento atribuindo-lhe uma alegada "utilidade social” e "pedagógica” (ver Das 1995, 1997; Herzfeld 1992).

Se considerarmos os fenómenos de sofrimento social como "factos sociais totais" que acarretam consigo outras e diversas dimensões e questões interligadas - como as da saúde, do trabalho, do welfare, religiosas, políticas, morais, legais, éticas, culturais - e se considerarmos a experiência direta ou indireta do sofrimento por parte dos indivíduos, conseguimos vislumbrar toda a sua complexidade enquanto novo paradigma das ciências sociais e, de certa forma, a sua inefabilidade do ponto de vista fenomenológico. Elizabeth Challinor, no presente volume, procura pôr em diálogo as abordagens do sofrimento social e as dimensões subjetivas que permitem analisá-lo mais proficuamente, tentando ainda situar-se, através de uma etnografia densa, nas tensões entre os aspetos universais e individuais da experiência humana. A sugestão de que o sofrimento pode resultar de dinâmicas intersubjetivas de posicionamento social e de uma matização identitária alerta o nosso olhar para os aspetos processuais do próprio sofrimento (ver Biehl, Good e Kleinman 2007). ${ }^{4}$

4 "O sujeito é ao mesmo tempo produto e agente da história, o lugar da experiência, memória, narrações e juízos estéticos; um agente de conhecimento assim como de ação; e o lugar conflituoso de atos e gestos morais no meio de sociedades e instituições incrivelmente amorais. [...]. Todavia a subjetividade não é só o resultado do controle social ou do inconsciente; mas também constitui o terreno para os sujeitos refletirem através das circunstâncias e sentirem através das contradições e, desta forma, suportarem interiormente experiências que, diversamente, e por fora, seriam insustentáveis" (Biehl, Good e Kleinman 2007: 14). 
Embora não diretamente abordados pelos autores do dossiê, os estudos sobre refugiados (e não nos referimos aqui necessariamente ao âmbito mais institucionalizado dos refugees studies) são exemplos claros e dramáticos de alguns aspetos que nos interessa introduzir e que estão diretamente ligados à temática do sofrimento social e da violência estrutural: primeiro, a forma paradoxal como é retirado ou atribuído o poder às pessoas (ver Harrell-Bond 1999); segundo, a apropriação, por parte das instituições que criam as condições para que o sofrimento tenha lugar, das teorias "salvíficas" sobre a utilidade do sofrimento com vista a um bem-estar maior e futuro da humanidade (ver Das 1997; e a "violência do zelo" de Lock 2000); e, finalmente, a evidência de quanto a assistência, os cuidados, o Estado-social, a proteção humanitária e até os direitos podem ser manipulados e imbricados na definição e organização das modalidades de pertença ou exclusão nacional (ver Bauman 2005 [2004]; Van Aken 2005), até ao extremo da redução do indivíduo à sua "vida nua" (Agamben 1995).

O que se pretende defender é uma nova forma de olhar para o sofrimento (e para as pessoas que sofrem) e uma antropologia virada, não somente para a análise dos mecanismos que criam sofrimento, mas também para a intervenção ao nível político, social e económico. Esta antropologia pretende investigar e problematizar as dinâmicas através das quais forças sociais como pobreza, racismo, diferenças de género, migração, heranças coloniais e exclusão social são incorporadas como fatores de risco e patologia, recusando um relativismo extremo como resposta fácil a um universalismo ingénuo e problemático.

De facto, a articulação entre história, política e sociedade está, muitas vezes, ausente das análises antropológicas que interrogam as linguagens múltiplas do corpo e do sofrimento; e a erosão destas áreas do saber representa provavelmente o problema central que uma antropologia do sofrimento, que se queira crítica e politicamente engajada, deve enfrentar.

Bauman (2005 [2004]: 84-85) sublinha como, a partir dos anos 80, assistimos a uma grande transformação na moderna organização da ordem e do progresso mundial, cuja consequência fatal, entre outras, se refere à "passagem de um modelo de comunidade inclusivo, inspirado no 'Estado social', a um Estado exclusivo, inspirado na 'justiça penal' e no 'controle da criminalidade". ${ }^{5}$

$\mathrm{O}$ artigo de Paulo Artur Malvasi é um claro exemplo: a sua etnografia, enquanto antropólogo e diretor de uma ONG em São Paulo, introduz-nos nas dobras ambíguas do processo institucional de "criminalização das periferias" e dos "jovens em risco" que nelas habitam. As medidas socioeducativas para jovens "marginais" são alvo de uma reflexão "militante"

5 A alusão às "instituições totais" de Goffman parece-nos aqui evidente.

6 No seu "Rumo a um campo intermédio militante", Herzfeld (2008 [2005]: 271) critica, de certa forma, o debate ciência-moralidade por conduzir a um binarismo, que ele define como pernicioso, porque sustenta "a prescrição ética sobre o grau apropriado do envolvimento político dos antropólogos nas questões morais respeitantes às sociedades que estudam”. 
dentro e desvendar os processos complexos e contraditórios de uma política institucional dirigida aos cuidados e à reinserção de indivíduos sob cujo perfil se esconde um discurso de vitimização das suas vítimas, moralização, psicologização e medicalização.

A este propósito, Herzfeld (2006 [2001]: 265) interroga-se sobre o papel da antropologia face a uma reformulação possível do social, no sentido de este se tornar um lugar de cuidados, acolhimento e conforto e não somente de punição, culpa e regulamentação. Este, no fundo, é o mesmo apelo de Das (1997) quando alerta sobre a possibilidade de as ciências sociais facilitarem a reprodução do silêncio das sociedades face ao sofrimento, como se existisse, denuncia Renault (2008: 25-26), "um efeito em espiral entre a invisibilidade, o caráter indizível e os obstáculos à mobilização".

Esta antropologia, noutras palavras, socialmente responsável, propõe interrogar-se incessantemente sobre os seus próprios instrumentos e interpretações, animada por uma reflexividade que não se limita à questão da subjetividade do antropólogo, mas que defende o empenho político do pesquisador. Uma leitura antropologicamente sensível do sofrimento é portanto uma questão política e uma responsabilidade ética em relação a atores sociais, tantas vezes silenciados, e que consideramos, antes de tudo, como sujeitos políticos e morais que, muitas vezes, manifestam sintomas produzidos pela estrutura social, pelas suas desigualdades ou pelas profundas feridas da história. ${ }^{7}$

O poder que se procura analisar, todavia, não entra em jogo somente para produzir as condições que favorecem a exclusão social, mas também para criar respostas institucionais e políticas de intervenção adequadas ao sofrimento que se propõe aplacar. Seguindo a proposta de Fassin $(2005$, 2006), um dos maiores desafios atuais consiste em investigar as políticas contemporâneas, não tanto nas suas instituições e técnicas, quanto no ethos que as anima e que Fassin (2005) define como "ethos da compaixão": trata-se de políticas que se empenham em aliviar o sofrimento, afastando o olhar das suas próprias causas.

Sofrimento social é, de facto, um conceito muito utilizado hoje, não somente nas ciências sociais, mas também nos programas governamentais e não governamentais de apoio social, e que abrange aspetos diferentes relacionados com a perda de qualidade de vida, podendo ser vivenciado tanto no plano individual quanto no plano coletivo.

7 Acreditamos que seja necessário que a antropologia reflita sobre o seu papel, não somente para explorar as formas como pode tornar evidente e significativo o sofrimento, mas também para conseguir dialogar com as perspetivas e as "possibilidades" de todos os atores, inclusive os institucionais que, frequentemente até pela própria análise e crítica antropológica, se encontram subsumidos e cristalizados nos seus próprios papéis - muitas das abordagens antropológicas de matriz foucaultiana têm sublinhado sobretudo a agência das "vítimas" do poder institucional, perdendo de vista frequentemente a dimensão plural, contraditória, paradoxal, das próprias estruturas institucionais e burocráticas. 
A retórica da "qualidade de vida" que informa estes programas, entendida em termos morais, além de materiais, representa a instigação contemporânea de uma intervenção destinada a uma maior inserção e realização pessoal (empowerment) das faixas vulneráveis da população, com uma maximização da segurança pública. A população "em risco" é também uma população "de risco", que ameaça, que contagia, segundo uma lógica caracterizada, por um lado, por "discursos sobre direitos e empowerment" e, por outro, por "discursos sobre o contágio e o controlo" (Seidel 1993).

As populações ou os indivíduos "em excesso", que todavia permanecem dentro dos confins dos Estados, necessitam de ser "alojados" ou, mantendo a metáfora baumaniana, "reciclados", de forma a que a sua anómala estranheza e exclusão sejam rapidamente reintegradas através dos "cuidados" e da reabilitação.

O caso de Lucas, analisado por Ana Paula Serrata Malfitano, introduz-nos nos meandros da legislação brasileira sobre crianças e adolescentes e sobre os conceitos de tutela/autonomia quando estes colidem com as experiências subjetivas dos "jovens", alvo de políticas sociais específicas. Perder ou ganhar a possibilidade de construir um percurso de autonomia - sendo a tutela assegurada só até à maioridade - é um dos danos colaterais incalculáveis de tais políticas, que perpassam as questões ligadas às desigualdades económicas, arriscando esvaziar, de tal forma, os sentidos teóricos da proteção e da tutela.

O sofrimento social aparece aqui, por um lado, como um "empecilho", que obriga as instituições a enquadrar médica e psicologicamente os jovens num quadro sintomatológico "normal", para que eles possam ter acesso a algum nível de cuidado; por outro, surge como uma variável, quase imprevisível, que só pode ser gerida se o jovem decide "aderir" a um percurso fortemente institucionalizado e "institucionalizante", no qual, de facto, pode acabar por encontrar um lugar, mesmo que de sofrimento, no mundo.

Os destinatários das intervenções sociais têm efetivamente poucas formas de acesso às respostas do Estado. Por um lado, estão relegados para as margens, sendo ao mesmo tempo vítimas e ameaças da estrutura; por outro, é exatamente esta posição de exclusão e marginalização que os torna recetores de intervenção social. A única forma que eles têm de aceder a uma modernidade individualizante é apresentar uma patologia social: Nguyen (2008) define esta condição como "cidadania humanitária", isto é, a constituição de sujeitos detentores de direitos e responsabilidades na base de uma específica condição social.

O conceito de "cidadania humanitária" aproxima-se do conceito de "biolegitimidade" proposto por Fassin (2001) para refletir sobre as contradições das políticas francesas destinadas aos imigrantes não documentados, inexistentes como detentores de direitos civis, a não ser quando esteja em jogo a preservação da sua existência orgânica. É enquanto “vida nua" (Agamben 1995) que o imigrante (ou o pobre, o marginal, o vulnerável, etc.) obtém os direitos de 
cidadão que, de outra forma, lhe seriam negados, e pode reivindicar com veemência a sua presença na sociedade.

A marginalidade, a dor, a doença, até a morte tornam-se assim terreno para uma revindicação de direitos, exatamente através da exclusão de uma vida socialmente significativa. Pandolfi (2005) define a "biocidadania" como uma modalidade de inclusão produzida por e produtora de formas subtis de exclusão; é justamente nas contradições do neoliberalismo global que os excluídos, os homines sacri (Agamben 1995), assumem diferentes formas, podendo ser considerados, ao mesmo tempo, vítimas que precisam de ajuda, perigos que devem ser controlados ou, ainda, agentes de formas inéditas de ação política (Comaroff 2007). Esta ambivalência justifica uma intervenção maciça nos segmentos mais precários e indesejáveis da sociedade, que visa ajudar os sujeitos na construção dos seus próprios projetos de vida para se tornarem cidadãos bem integrados na ordem social e moral dominante.

Surge nesta lógica uma nova espécie de pacto social entre os marginais, que devem fazer o possível para se integrarem, e os especialistas (psicólogos, assistentes sociais, educadores, mas também sociólogos e antropólogos), que se disponibilizam para aliviar o sofrimento daqueles, ajudando-os a construir novos projetos de vida. ${ }^{8}$ Este pacto particular constitui, nas palavras de Isabelle Astier (1996: 99), "um dispositivo que favorece uma vasta empresa de exploração da intimidade das pessoas": o destinatário da intervenção social deve, quer expor a sua própria infelicidade, quer dispor-se a repensar o passado e a imaginar o futuro, para mudar a precariedade do presente e para poder obter o apoio esperado.

O sofrimento, a dor, a violência - enquanto fenómenos sociais, mas também enquanto instrumentos conceptuais e analíticos -, tal como as intervenções a seu favor e por eles justificadas, estão a ser cada vez mais submetidos a processos, por um lado, de progressiva institucionalização, por outro, de mediatização e hipervisibilização (ver Kleinman e Kleinman 1996), processos que evidenciam o seu potencial ambivalente e perigoso e a sua relevância enquanto assunto político, no sentido mais amplo do termo. Não são já algo escondido ou silenciado, mas, pelo contrário, são expostos, comentados, monitorizados, estudados - segundo lógicas que refletem obviamente realidades económicas e de financiamento e interesses governamentais específicos. Dentro deste quadro de sofrimento "amplificado", multiplicam-se as reuniões profissionais

8 Estamos a falar de todas aquelas tecnologias do self implementadas através da disciplina dos corpos, que produzem "bons" cidadãos. Citamos entre elas: as instituições disciplinares (escolas, hospitais, prisões), que educam o corpo; as capitalistas (fábricas, exércitos, empresas), que orientam o corpo numa direção produtiva; e as práticas do self (educação moral, sexual, alimentar, exercício físico, psicoterapia), que constroem sujeitos adequados às expectativas da ordem dominante (para uma análise completa, ver Rose 1996, 1999, 2006). 
e científicas, as publicações (este dossiê é um claro exemplo disto mesmo), os projetos, os pedidos institucionais de formação e expertise específicas, os dispositivos de avaliação e diagnósticos, os centros de apoio e as organizações destinadas a responder ao escândalo do sofrimento.

O sofrimento - comenta ironicamente Jackie Assayag (1999) - "coloniza hoje o nosso futuro com os seus pesadelos" e a análise das respostas disponíveis no mercado assistencial não pode ignorar as dimensões políticas, económicas e morais em jogo. A "psicologização do social” (Fassin 2005) é uma destas dimensões: a psicologia torna-se o instrumento principal através do qual se intervém nas situações de pobreza, marginalidade e violência, e os psicólogos operam para curar as feridas das periferias, dos segmentos marginais da população. As leituras e as lógicas contemporâneas destinadas a tratar os sintomas do sofrimento concentram-se hoje mais no léxico do apoio e do empowerment, criando um consenso geral que desarma a crítica: a compaixão não tem inimigos.

Como demonstra o artigo de Rubens de Camargo Ferreira Adorno, sobre as populações em situação de rua, os programas de apoio social gravitam em torno daquela a que podemos chamar a dicotomia vulnerabilidade/risco. Por um lado, impõe-se uma representação que costuma relacionar os marginais com o desvio e a criminalidade, a falta de competências sociais e a insegurança, associando-os, deste modo, à ideia de risco que eles próprios simbolizam para o resto da sociedade. Por outro, divulga-se uma imagem dos mesmos sujeitos como pessoas em dificuldade, vítimas de uma estrutura desigual, necessitados e desprotegidos, num estado permanente de vulnerabilidade.

As soluções propostas para responder à questão impertinente do sofrimento social gravitam à volta de ações que têm por objetivo cuidar dos vulneráveis e, ao mesmo tempo, controlar os riscos desta vulnerabilidade. Estas oscilações entre representações de vulnerabilidade e risco, de vítimas e criminosos, de apoio e preocupação, de políticas da piedade e de controlo, tornam-se particularmente evidentes analisando as intervenções na vida dos imigrantes não documentados (Fassin 2001), dos pobres urbanos (Geremek 1987 [1978]; Wacquant 1999), ou dos jovens dos bairros sociais (Fassin 2004). Segundo Fassin $(2005,2006)$, trata-se de uma polarização moral entre compaixão e repressão, onde o processo de "securização" se articula com as lógicas da intervenção social.

A "Cracolândia" paulistana, onde Bruno Ramos Gomes desenvolveu a sua pesquisa, é um lugar de "exposição" dos corpos, das ações e da intimidade dos usuários (os "noias") e vendedores de crack que sofrem com a constante presença de intervenções militares, altamente performáticas e mediatizadas, de vários agentes da assistência social e da saúde, e de fiscais da vigilância sanitária, funcionários de companhias de energia elétrica, de gás e saneamento, com vista à requalificação da área. Todavia, a persistência dos "noias" na região é 
descrita como uma forma de resistência "tática" que acaba por incorporar, de facto, a identidade específica que lhes é atribuída e que se torna um "valor".

A antropologia, portanto, deverá aceitar o desafio provocador lançado por Herzfeld (2006 [2001]: 286): queremos, de facto, ceder "toda a agência às agências?"

\section{BIBLIOGRAFIA}

AGAMBEN, Giorgio, 1995, Homo Sacer: Il Potere Sovrano e la Nuda Vita. Turim, Einaudi.

ASSAYAG, Jackie, 1999, recensão de Social Suffering (Arthur Kleinman, Veena Das e Margareth Lock, 1997, Berkeley, University of California Press), L'Homme, 149: 214-218.

ASTIER, Isabelle, 1996, “Le contrat d'insertion: une façon de payer de sa personne?”, Politix, 34: 99-113.

BAUMAN, Zygmunt, 2005 [2004], Vite di Scarto. Roma-Bari, Laterza.

BIBEAU, Gilles, 1995 [1981], "Premesse per un'epidemiologia antropologica della depressione”, em Roberto Beneduce e René Collignon (orgs.), Il Sorriso della Volpe: Lutto, Ideologie della Morte e Depressione in Africa. Nápoles, Liguori, 41-59.

BIEHL, João, Byron GOOD, e Arthur KLEINMAN, 2007, "Introduction: rethinking subjectivity”, em João Biehl, Byron Good e Arthur Kleinman (orgs.), Subjectivity: Ethnographic Investigations. Berkeley e Los Angeles, University of California Press, 1-24.

COMAROFF, Jean, 2007, "Beyond the politics of bare life: AIDS and the global order", Public Culture, 19 (1): 197-219.

DAS, Veena, 1995, Critical Events: An Anthropological Perspetive on Modern India. Deli, Oxford University Press.

—, 1997, "Suffering, theodicies, disciplinary practices, appropriations", International Social Sciences Journal, 154: 563-572.

FARMER, Paul, 2004, "An anthropology of structural violence", Current Anthropology, 45 (3): 305-325.

FASSIN, Didier, 2001, “The biopolitics of otherness: undocumented immigrants and racial discrimination in the French public debate", Anthropology Today, 17 (1): 3-7.

—, 2004, Des maux indicibles: Sociologie des lieux d'écoute. Paris, La Decouverte.

— 2005, "Compassion and repression: the moral economy of immigration policies in France”, Cultural Anthropology, 20 (3): 362-387.

—, 2006, "Souffrir par le social, gouverner par l'écoute: une configuration", Politix, 73: 137-157.

GEREMEK, Bronislaw, 1987 [1978], La potence ou la pitié: L'Europe et les pauvres du Moyen Age. Paris, Gallimard.

HARRELL-BOND, Barbara, 1999, "The experience of refugees as recipients of aid", em Alastair Ager (org.), Refugees: Perspetives on the Experience of Forced Migration. Londres, Pinter, 136-168. 
HERZFELD, Michael, 1992, The Social Production of Indifference: Exploring the Symbolic Roots of Western Bureaucracy. Oxford, Berg.

—, 2006 [2001], Antropologia: Pratica della Teoria nella Cultura e nella Società. Florença, SEID Editori.

—, 2008 [2005], Intimidade Cultural: Poética Social no Estado-Nação. Lisboa, Edições 70.

KLEINMAN, Arthur, Veena DAS, e Margareth LOCK, 1997, Social Suffering. Berkeley, University of California Press.

KLEINMAN, Arthur, e Joan KLEINMAN, 1996, "The appeal of experience; the dismay of images: cultural appropriations of suffering in our time", Daedalus, 125 (1): 1-25.

LOCK, Margareth, 2000, "The quest for human organs and the violence of zeal”, em Veena Das, Arthur Kleinman, Mamphela Ramphele e Pamela Reynolds (orgs.), Violence and Subjectivity. Berkeley, University of California Press, 27 1-295.

NGUYEN, Vinh-Kim, 2008, "Antiretroviral globalism, biopolitics, and therapeutic citizenship", em Aihwa Ong e Stephen J. Collier (orgs.), Global Assemblages: Technology, Politics, and Ethics as Anthropological Problems. Oxford, UK, Blackwell Publishing, 124-144.

PANDOLFI, Mariella, 2005, "Sovranitá mobile e derive umanitarie: emergenza, urgenza e ingerenza”, em Roberto Malighetti (org.), Oltre lo Sviluppo: Le Prospettive dell'Antropologia. Roma, Meltemi, 151-185.

RENAULT, Emmanuel, 2008, Souffrances sociales: Philosophie, psychologie et politique. Paris, La Découverte.

ROSE, Nikolas, 1996, Inventing Our Selves: Psychology, Power and Personhood. Nova Iorque, Cambridge University Press.

—, 1999, Governing the Soul: The Shaping of the Private Self. Londres, Free Association Books.

—, 2006, The Politics of Life Itself: Biomedicine, Power, and Subjectivity in the Twenty-First Century. Princeton, NJ, Princeton University Press.

SEIDEL, Gill, 1993, "The competing discourses of HIV/AIDS in Sub-Saharan Africa: discourses of rights and empowerment vs discourses of control and exclusion”, Social Science and Medicine, 36 (3): 175-194.

SEN, Amartya, 1985, Commodities and Capabilities. Amesterdão, North-Holland.

—, 2005, "Human rights and capabilities", Journal of Human Development, 6 (2): 151-166.

—, 2009, The Idea of Justice. Cambridge, MA, Harvard University Press.

VAN AKEN, Mauro (org.), 2005, "Rifugiati”, Annuario Antropologia, 5 (5): 5-10.

WACQUANT, Loïc, 1999, Les prisons de la misère. Paris, Raisons d'Agir.

Social suffering: languages of exclusion and welfare policies - Chiara Pussetti - Centro em Rede de Investigação em Antropologia (CRIA-IUL), Instituto Universitário de Lisboa, Portugal chiaragemma.pussetti@gmail.com • • Micol Brazzabeni • Centro em Rede de Investigação em Antropologia (CRIA-IUL), Instituto Universitário de Lisboa, Portugal • brazzabeni.mic@gmail.com

The concept of social suffering has emerged in recent decades as a new paradigm in social sciences and as a particularly appropriated lens to look at the deep relationships between the subjective experience of malaise and the broader historical and social processes. This article and the contributions gathered in this dossier aim to address social suffering from three different basic points of view: 1) the paradoxical form by which power is taken from or given to the people; 2) the appropriation, by the institutions 
that create the conditions for that suffering to take place, of "salvific" theories about the usefulness of suffering in order to achieve a greater and future well-being of humanity; 3 ) the evidence of the extent to which care and cure, the welfare-state, humanitarian protection, or even rights can be manipulated and intertwined in the definition and organization of the modalities of national belonging or exclusion, to the extreme reduction of the individual to his "bare life".

KEYWORDS: social suffering, agency and subjectivity, welfare policies. 